\title{
Review: Sensor Impact on Building Controls and Automatic Fault Detection and Diagnosis (AFDD)
}

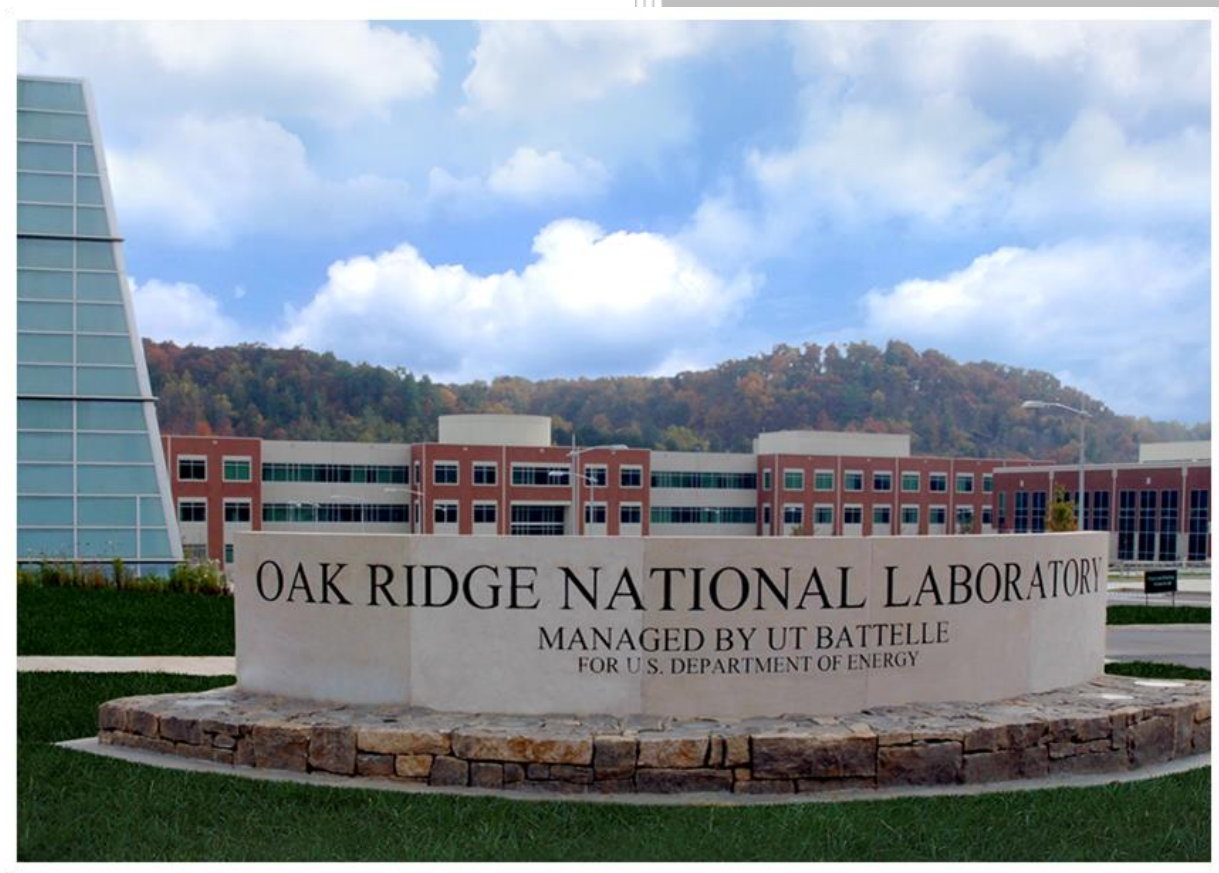

Yeonjin Bae, Ph.D. Borui Cui, Ph.D. Jaewan Joe, Ph.D. Piljae Im, Ph.D. Veronica Adetola, Ph.D. Liang Zhang, Ph.D. Matt Leach Teja Kuruganti, Ph.D. 


\title{
DOCUMENT AVAILABILITY
}

Reports produced after January 1, 1996, are generally available free via US Department of Energy (DOE) SciTech Connect.

Website http://www.osti.gov/scitech/

Reports produced before January 1, 1996, may be purchased by members of the public from the following source:

\author{
National Technical Information Service \\ 5285 Port Royal Road \\ Springfield, VA 22161 \\ Telephone 703-605-6000 (1-800-553-6847) \\ TDD 703-487-4639 \\ Fax 703-605-6900 \\ E-mail info@ntis.gov \\ Website http://www.ntis.gov/help/ordermethods.aspx
}

Reports are available to DOE employees, DOE contractors, Energy Technology Data Exchange representatives, and International Nuclear Information System representatives from the following source:

Office of Scientific and Technical Information

PO Box 62

Oak Ridge, TN 37831

Telephone 865-576-8401

Fax 865-576-5728

E-mail reports@osti.gov

Website http://www.osti.gov/contact.html

This report was prepared as an account of work sponsored by an agency of the United States Government. Neither the United States Government nor any agency thereof, nor any of their employees, makes any warranty, express or implied, or assumes any legal liability or responsibility for the accuracy, completeness, or usefulness of any information, apparatus, product, or process disclosed, or represents that its use would not infringe privately owned rights. Reference herein to any specific commercial product, process, or service by trade name, trademark, manufacturer, or otherwise, does not necessarily constitute or imply its endorsement, recommendation, or favoring by the United States Government or any agency thereof. The views and opinions of authors expressed herein do not necessarily state or reflect those of the United States Government or any agency thereof. 
Energy and Transportation Science Division

\title{
Review: Sensor Impact on Building Controls and Automatic Fault Detection and Diagnosis (AFDD)
}

\author{
Yeonjin Bae, Ph.D. \\ Borui Cui, Ph.D. \\ Jaewan Joe, Ph.D. \\ Piljae Im, Ph.D. \\ Veronica Adetola, Ph.D. \\ Liang Zhang, Ph.D. \\ Matt Leach \\ Teja Kuruganti, Ph.D.
}

\author{
Prepared by \\ OAK RIDGE NATIONAL LABORATORY \\ Oak Ridge, TN 37831-6283 \\ managed by \\ UT-BATTELLE, LLC \\ for the \\ US DEPARTMENT OF ENERGY \\ under contract DE-AC05-00OR22725
}





\section{CONTENTS}

CONTENTS

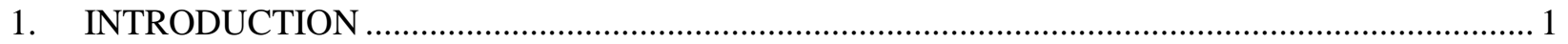

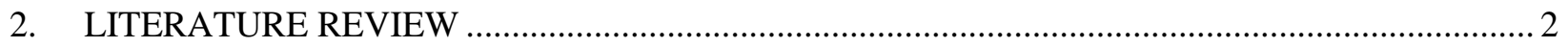

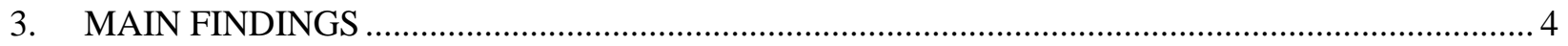

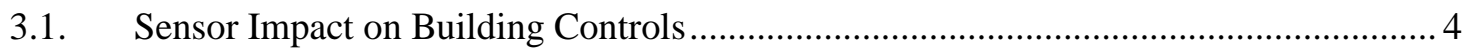

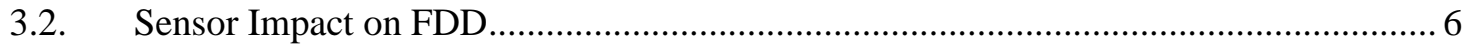

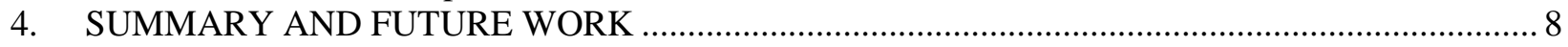

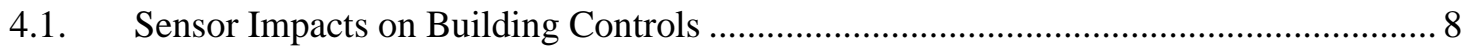

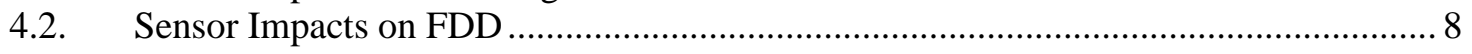

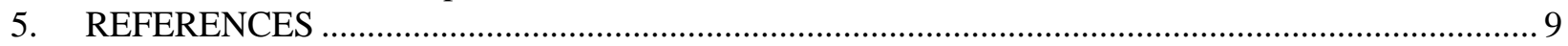




\section{FIGURES}

Figure 1: Schematic flow of the project....................................................................................... 1

Figure 2: Categorized review work for building controls and FDD by type, methodology, and

Figure 3: Categorized review work for building controls and FDD by building type and system

layer. 


\section{INTRODUCTION}

This report summarizes a literature review as a Q1 deliverable of the "Sensor Impact Evaluation and Verification" project.

This project's overarching goal is to develop a framework for investigating the impact of sensor deployment and configuration for building energy optimization, fault detection and diagnosis (FDD), occupants' thermal comfort, and potential grid efficiency. The proposed project flow is shown in Figure 1 .

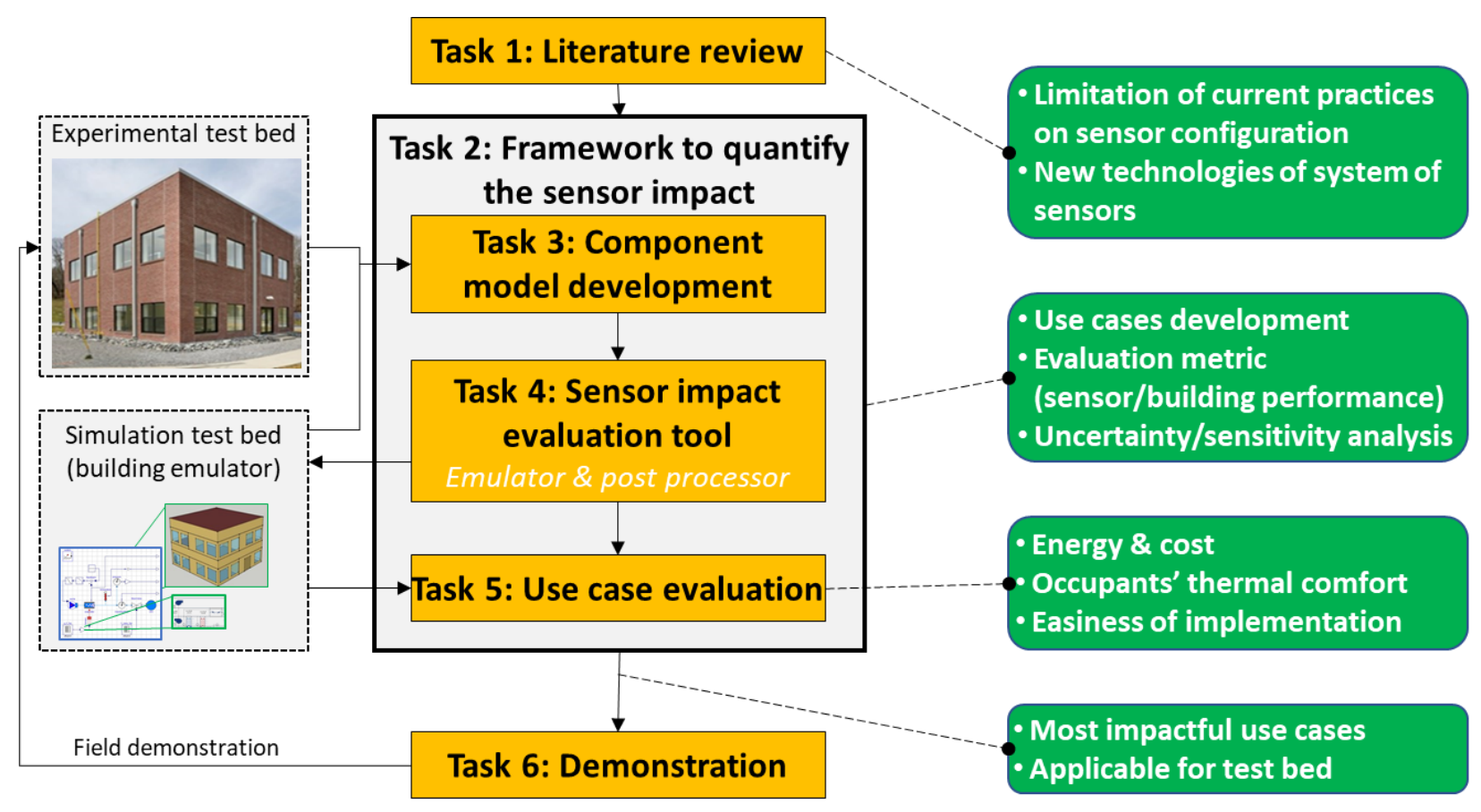

Figure 1: Schematic flow of the project.

The project's first task was a literature review, which established a solid knowledge of and a background related to sensor technologies and placement. To accomplish this, an extensive literature review of previous research and a survey of current industry practices were performed. The literature review of sensor technologies and placement was expected to contribute to (1) understanding the previous and current research, (2) identifying research gaps in current and previous work, and (3) investigating the potential impacts on building performance.

During Q1, the multi-lab team reviewed 65 research papers, technical reports, and related books to identify the current methods of sensor selection and placement. This report categorizes the review work for building controls and automatic FDD and summarizes the main findings. In Q2, the team will continue the literature review for building controls and FDD based on selected sensor suites. The team will also conduct a series of interviews and/or surveys to further investigate the current status and limitations of sensor configuration. 


\section{LITERATURE REVIEW}

During the literature review, the team categorized the literature by topic (i.e., control-related or FDD related), research methodology (i.e., simulation, experiment, review, or guideline), priority (i.e., 1, 2, 3, or 4), building type (i.e., residential or commercial), and system layer (i.e., room, heating, ventilation, and air conditioning (HVAC), or building), as shown in Figure 2.

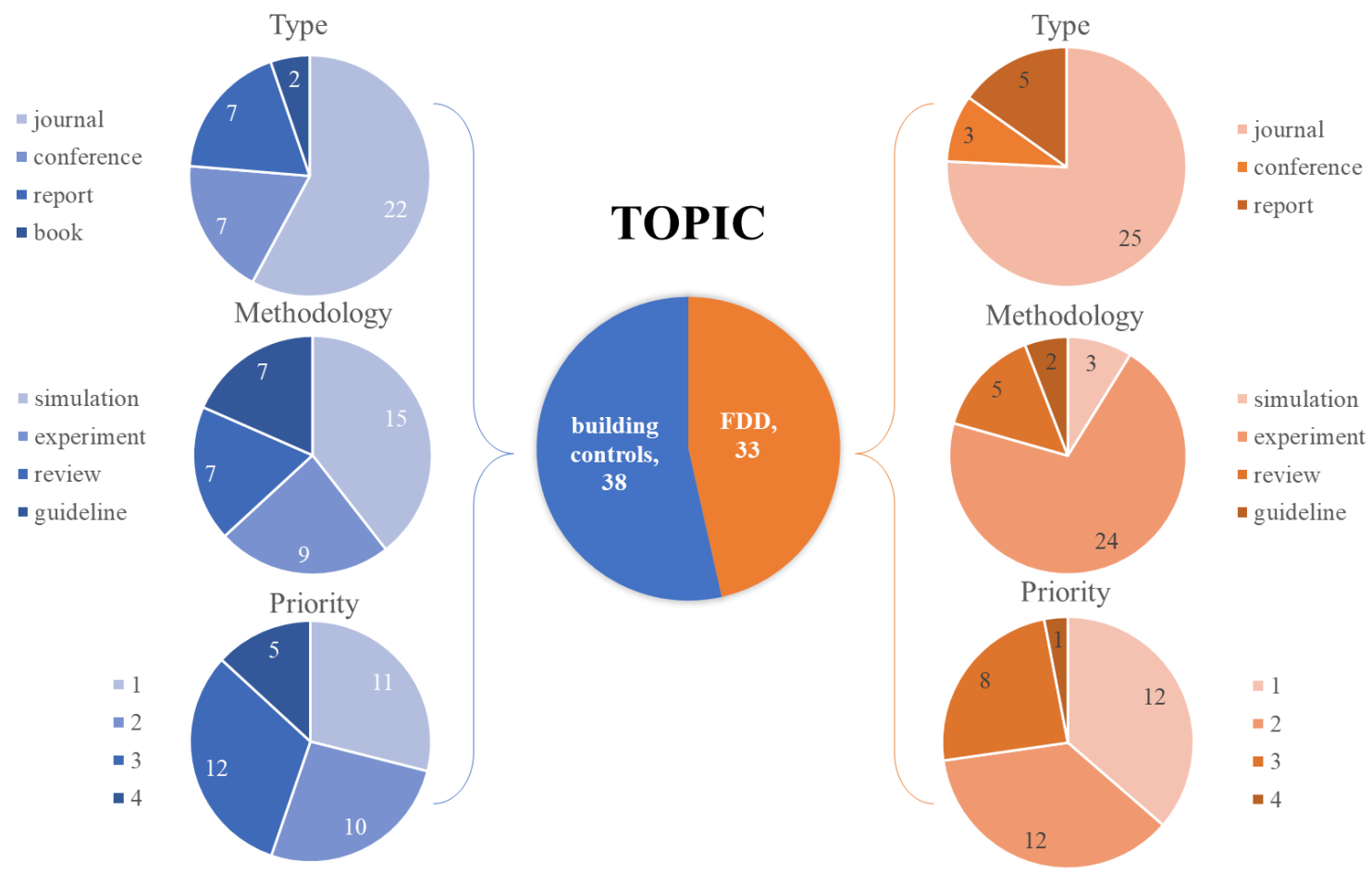

Figure 2: Categorized review work for building controls and FDD by type, methodology, and priority.

The review work methodologies were also categorized for building controls and FDD, as shown in Figure 2. Some references could be classified into multiple categories. For example, if research was performed for both simulation study and experimental study, then the reference was categorized into both simulation and experimental study.

The literature's priority was set by examining the main theme and topic, methodology, and application, as shown in Figure 2. If the main topic of the literature was closely aligned with the project goal, then priority 1 was assigned. If the literature contained useful information, such as a rule, practice, or norm in terms of the sensor design or configuration, then priority 2 was assigned. If any useful information was found, including a keyword, definition, methodology, term, or related application, then priority 3 was assigned. If useful information was hardly found, or it was off-topic, then priority 4 was assigned.

Journal papers were a main source for the literature review, followed by conference papers and reports. For the building controls-focused review, $40 \%$ were simulation studies and $30 \%$ were experimental studies, whereas the FDD-focused literature reviews were $70 \%$ experimental studies. In the priority categorization, $60 \%$ were priority 1 and 2 for building controls-focused reviews, and $75 \%$ were priority 1 and 2 for FDD reviews. 
The review work was also categorized by building type and system layer, as shown in Figure 3. Few studies were found to have been performed in the residential building sector (i.e., $20 \%$ for building controls research and $8 \%$ for FDD research). In the system layer classification, most FDD works were confined to the HVAC layer, whereas the room and HVAC layer were more than $87 \%$ in the building controls works.

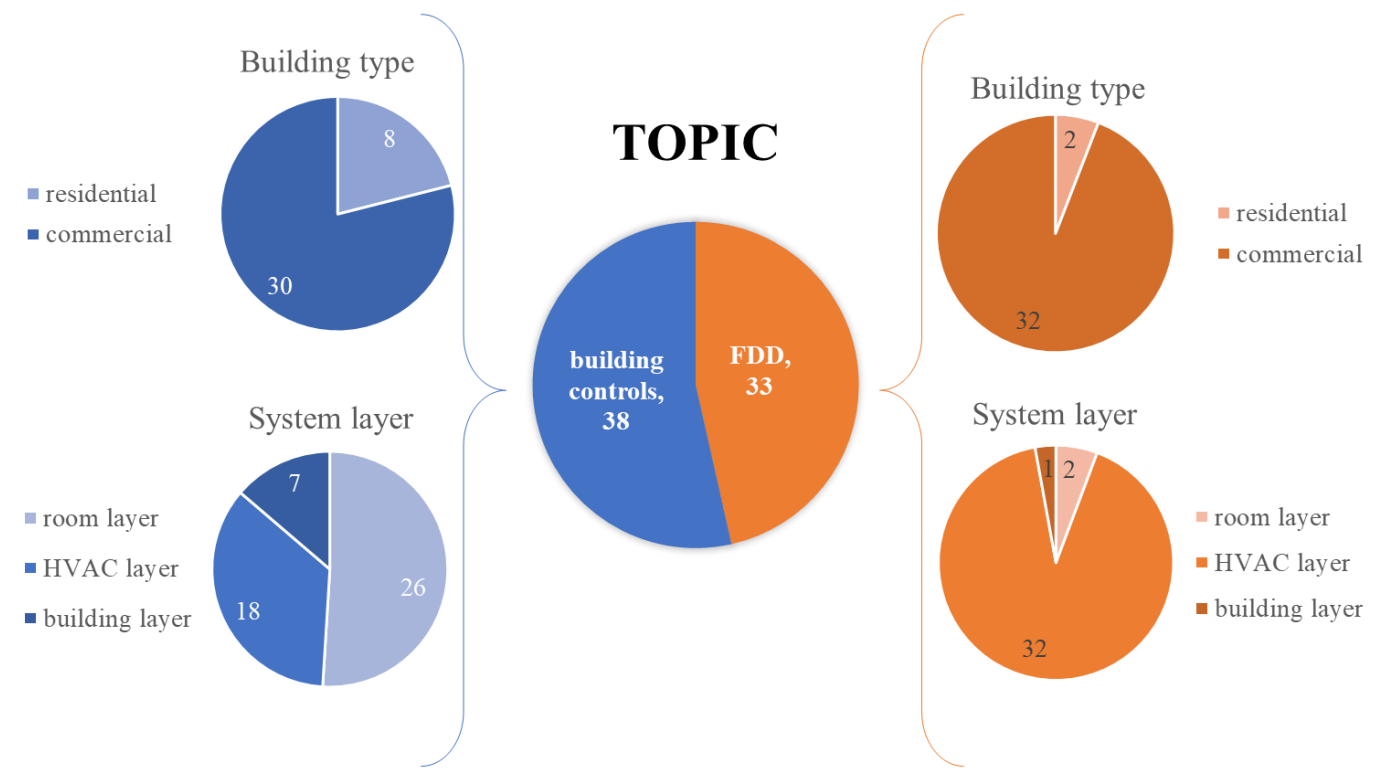

Figure 3: Categorized review work for building controls and FDD by building type and system layer. 


\section{MAIN FINDINGS}

This section describes the literature review summary and the main findings of the sensor impacts on building controls and FDD.

\subsection{Sensor Impact on Building Controls}

\section{- Most studies focused on applications in commercial or public buildings.}

Most papers and reports focused on experiment and simulation study in commercial buildings and public buildings (e.g., offices, retail, hotels, hospitals, classrooms, libraries, study areas). Only a few research papers focused on residential buildings as reference building targets [8, 13, 29, 34].

\section{- Most sensors investigated in building controls included the sensors for the room layer and building layer.}

Frequently investigated sensors in the literature can be summarized as follows.

- Room layer (e.g., thermostat [3, 15, 18, 37, 39], occupancy sensor [3, 11, 13], $\mathrm{CO}_{2}$ sensor $[3,6,13,20]$, volatile organic compound sensor, lighting sensor $[2,3,12])$

- HVAC layer (e.g., temperature sensor [2, 35], air flow meter [9, 12], static pressure sensor [15])

- Building layer (e.g., total energy consumptions, power meter [3, 5, 8])

- Sensor requirements and configurations are normally from codes, standards, and reports. Applications in variable air volume (VAV) systems are a key research subject.

Important standards and codes (e.g., Sensor Characteristics Reference Guide [PNNL-22484]; ASHRAE Standards 90.1, 90.2, 55, 62.1, and 189.1; International Energy Conservation Code; International Building Code; National Fire Protection Association 5000 code) are foundations that support multiple types of sensors (e.g., HVAC, room, and building sensors) used in building subsystems that facilitate energy efficiency and cost savings [41]. These codes provide sensor locations and configuration requirements for a wide range of application scenarios, such as occupancy-based HVAC and lighting control, FDD, commissioning, indoor air quality control, ventilation, transactive energy, and renewable integration. A report by Kuruganti et al. introduced the gaps in sensor applications in building control and FDD research areas [42]. The potential sensor technologies and configurations proposed as solutions for different application examples are also provided in this report [42]. For example, low-cost, self-powered wireless sensors could be applied for fault detection in a large building in which it is costly to have multiple traditional temperature sensors. For the VAV system, the sensor requirements for different control strategies based on ASHRAE handbooks are proposed in Taylor et al. [10]. For example, a discharge air temperature sensor (an HVAC layer sensor) is needed in most cases. Extensive design information for HVAC layer sensors in the VAV system in commercial buildings [2] was introduced, including the recommended VAV minimum position (normally $\sim 30-50 \%$ ) and VAV control methods. The 
effect of sensor placement location on VAV system performance in terms of indoor thermal comfort (Predicted Mean Vote, PMV) and energy consumption was analyzed in Du et al. [35].

- Many studies investigated the optimization of sensor placement and the number of sensors in the HVAC layer and room layer for improving building energy performance and indoor thermal comfort.

Sensor locations and the number of sensors are generally selected based on engineering judgment or heuristic methods [28]. In previous studies, efforts were made to investigate how sensor locations affect building performance. Many studies used computational fluid dynamics (CFD) modeling or CFD/Modelica coupling. Tian et al. [18] optimized the locations of room layer sensors to maximize indoor thermal comfort (PMV) using CFD and Modelica. Bianco and Tisato [11] optimized the location of vision sensors to detect occupancy. The impact of different sensor types on HVAC system performance was also considered in recent studies. Liu et al. [15] suggested a method for optimizing sensor placement to reduce HVAC energy consumption. The space dimensions and sensor specifications, types, and locations were used as the inputs for optimization. Painter et al. [6] proposed a method to support building control commissioning and maintenance by providing higher resolution data and speeding up the commissioning process. Yoganathan et al. [38] used a clustering algorithm to determine optimal sensor coverage in an office building. Chen et al. [22] proposed a method for reducing the number of installed room layer sensors by developing virtual sensors that combine the prior knowledge of temperature statistics and Bayesian Model Fusion.

- Optimized sensor location and displacement and their impact on building systems must be investigated thoroughly.

The optimal number and location of sensors vary with sensor type. A separate sensor node, rather than a multi-sensor system, could be needed for optimality. Also, the optimal spatial location of temperature and humidity sensors could vary slightly with time [38]. The majority of the sensors in the building space might require optimization for their location/displacement to realize a considerable impact on system-level energy consumption. In a study by Du et al. [35], changing the sensor positions in one of the building's seven rooms resulted in an HVAC energy variation between -0.34 to $0.14 \%$ only. Therefore, a sensor placement retrofit in a small subset of the building might not affect the overall HVAC energy consumption (air side + water side).

Placing a temperature sensor for the VAV control loop at the return air inlet is not always the optimal solution [35]. During the cooling season, the required airflow increases when the sensor is placed at the return air duct [54] since the temperature in the return duct is usually higher than the zone temperature, which can lead to overcooling. The required supply airflow rate depends on how close the temperature sensor [35] is to the supply air diffuser versus the occupant and internal heat gain sources. Indoor thermal comfort (PMV) is most satisfied and energy usage is lower when the sensor is placed away from the return air inlet, the supply air outlet, or a heat source. When the room-level temperature sensor is placed near the diffuser [37], the required fan power is reduced, but the return air is warmer, resulting in a large cooling load and increasing chiller plant power consumption. 
- A few studies estimated the energy-savings potential of deploying various sensors and controls.

Using advanced thermostats, such as occupancy-based wireless thermostats and learning thermostats (\$150-330/thermostat), can save energy in office buildings by reducing HVAC energy consumption by $\sim 5-30 \%$ [3]. $\mathrm{CO}_{2}$ demand-controlled ventilation can achieve heating and cooling energy savings of up to $10 \%$ compared with typical building system designs. The initial system cost $(\sim 1-3 / \mathrm{cfm} /$ system $)$ would vary by design and outdoor air requirements, which are determined by occupancy and floor area. Advanced controls based on additional sensor deployment could also save energy. By replacing a conventional system with an advanced rooftop controller ( $\$ 2,000-4,000 /$ roof top unit, RTU) that enables economizing controls that use temperature sensors or real-time weather data, HVAC energy consumption can be reduced by up to $40 \%$. Implementing advanced control strategies (e.g., using optimal setpoint control [63] or model predictive control strategies $[64,65]$ ) can achieve cooling energy savings of up to $40 \%$. A tenant comfort feedback system or a cloud-based energy management information system can also achieve HVAC energy savings of $\sim 15-25 \%$.

\section{- Optimal selection and placement of certain sensors can improve thermal comfort.}

Optimal placement of thermostats can significantly improve occupants' comfort, but this could result in additional energy usage. An HVAC energy consumption increase of $\sim 8 \%$ was reported in a study that diagnosed and corrected poor comfort conditions by relocating thermostats in a restaurant equipped with multiple rooftop units [37].

Adding additional zones could also improve thermal comfort. Although adding zones could increase the cost of the mechanical systems by $\$ 3-6 / \mathrm{ft}^{2}$, an uncomfortable indoor environment could lead to operating personal space heaters and fans, which would consume more energy. Instead, sub-zoning with self-powered VAV diffusers can be a reasonably lower cost option, with an additional cost of $\sim \$ 200-250$ per diffuser [3].

\section{- Wireless sensor systems could reduce installation and integration costs in retrofit} applications.

Wireless sensor systems offer cost benefits and improved flexibility for retrofit applications. A 10-15\% reduction in installation cost was achieved with a wireless sensor network-based building HVAC control system compared with a conventional wired system [53]. Standalone devices might be more cost-effective than wireless sensors, but the resolution is not as great as expected. Integrating the existing sensor data and additionally installed sensors could be a challenge [6]

For the initial cost, the ownership structure for the cost should be considered [3], and sensor sets can be reused multiple times in different buildings for the commissioning process [6].

\subsection{Sensor Impact on FDD}

\section{- Current FDD research focuses more on FDD algorithms than sensors.}

Data-driven (or history-based) FDD models account for 62\% of FDD models from 197 research papers since 2004 [32]. The rapid development of machine-learning techniques empowers datadriven FDD models with good performance and high reliability. Data-driven FDD models with 
sophisticated machine-learning algorithms are hungry for data. They require higher data quantity, quality, and variety, and improved support from a sensor perspective is greatly needed.

Many studies applied very sophisticated machine-learning algorithms with existing sensors that are common to building automation systems. They focused more on the algorithm than the sensors. There is a gap between fast-developing FDD algorithms and a lack of support from a sensor perspective.

- Sensor selection, sensor faults, and virtual sensors are the main FDD study topics related to sensors.

Many studies discussed the sensor selection problem in FDD modeling. Sensor selection is a widely discussed topic in FDD for chillers [43, 47, 51], variable refrigerant flow systems [48], air handling units [49], and whole HVAC systems [45]. These sensor selection studies focused on selecting the sensor set used for FDD from existing sensors to improve FDD performance rather than installing new sensors. Sensor selection is widely studied, but sensor replacement is not; there are large opportunities for the future study of sensor replacement in FDD application.

Many studies focused on sensor faults in building HVAC systems [46, 56, 57]. Sensor faults greatly affect building energy efficiency [58] and have been identified as an important fault type in existing FDD studies.

The virtual sensor is also an important topic in FDD research [50, 52, 59]. Virtual sensing systems use the information available from other sensors and process parameters to calculate an estimate of the quantity of interest. Like sensor selection studies, virtual sensor technique research uses existing sensors instead of installing new sensors.

Other research topics, such as sensor location and distribution for FDD [59], the minimum number of required sensors for FDD [60], and low-cost sensors for FDD [61], exist but are not very widely discussed.

- Most FDD studies used existing sensor systems in buildings; very few studies focused on sensor design as an integral aspect of FDD development.

Very few studies addressed sensor design as part of FDD development. Some studies used simulation tools such as EnergyPlus and Modelica to simulate faults [62]. Since simulation tools have thousands of "virtual sensors," they can be used to decide which sensors are important for FDD, or they can apply sensor selection before the sensors are physically installed. Most FDD research is based on existing sensor systems in buildings. Tailoring sensor design and configuration to FDD algorithms is expected to substantially improve FDD performance. 


\section{SUMMARY AND FUTURE WORK}

The impact of sensor deployment and configuration for building energy optimization, FDD, and occupants' thermal comfort was investigated through an extensive literature review. The literature review on sensor selection and sensor placement contributed to (1) understanding the previous and current research, (2) identifying research gaps in the current and previous work, and (3) investigating the potential effects on building performance.

\subsection{Sensor Impacts on Building Controls}

- Most studies focused on applications in commercial or public buildings.

- Most sensors investigated in building controls included the sensors for the room layer and building layer.

- Sensor requirements and configurations are normally from codes, standards, and reports. Applications in VAV systems are a key research subject.

- Many studies investigated the optimization of sensor placement and the number of sensors in the HVAC layer and room layer for improving building energy performance and indoor thermal comfort.

- Optimized sensor location and displacement and their impact on building systems must be investigated thoroughly.

- A few studies estimated the energy-saving potential of deploying various sensors and controls.

- Optimal selection and placement of certain sensors can improve thermal comfort.

- Wireless sensor systems could reduce installation and integration costs in retrofit applications.

\subsection{Sensor Impacts on FDD}

- Current FDD research focuses more on FDD algorithms than sensors.

- Sensor selection, sensor faults, and virtual sensors are the main FDD study topics related to sensors.

- Most FDD studies used existing sensor systems in buildings; very few studies focused on sensor design as an integral aspect of FDD development.

To further understand current practices and to investigate the application of interest for sensor impact research, surveys and/or interviews will be performed. The literature review, as well as survey/interview results, will be documented in a journal paper (Q2 deliverable). The findings from the literature review and survey will also be used to define high-priority use cases, define evaluation metrics, and develop a framework for quantifying the sensor impact. 


\section{REFERENCES}

1. A. A. Bell and W. L. Angel. HVAC Equations, Data, and Rules of Thumb. New York, New York: McGraw-Hill (2000).

2. J. Stein, A. Zhou, and H. Cheng. “Advanced Variable Air Volume System Design Guide,” California Energy Commission's Public Interest Energy Research, USA (2007): 316.

3. C. Perry. "Smart Buildings: A Deeper Dive into Market Segments," American Council for an Energy-Efficient Economy Research Report A1703 (2017).

4. F. Wang, H. Lin, and J. Luo. "Energy Consumption Analysis with a Weighted Energy Index for a Hotel Building," Procedia Engineering 205 (2017): 1,952-1,958.

5. S. Treado and Y. Chen. "Saving Building Energy through Advanced Control Strategies," Energies 6, no. 9 (2013): 4,769-4,785.

6. B. Painter, N. Brown, and M. J. Cook. "Practical Application of a Sensor Overlay System for Building Monitoring and Commissioning," Energy and Buildings 48 (2012): 29-39.

7. R. B. Farrington and C. V. Wells. Thorough Approach to Measurement Uncertainty Analysis Applied to Immersed Heat Exchanger Testing (No. SERI/TP-253-2862; CONF-860406-7). Solar Energy Research Inst., Golden, Colorado (1986).

8. C. Spitz, L. Mora, E. Wurtz, and A. Jay. "Practical Application of Uncertainty Analysis and Sensitivity Analysis on an Experimental House," Energy and Buildings 55 (2012): 459-470.

9. M. R. Brambley, N. Fernandez, W. Wang, K. A. Cort, H. Cho, H. Ngo, and J. K. Goddard. Final Project Report: Self-Correcting Controls for VAV System Faults Filter/Fan/Coil and VAV Box Sections (No. PNNL20452). Pacific Northwest National Laboratory, Richland, Washington (2011).

10. S. Taylor et al. "VAV System Design Tips," Air System Engineering \& Technology Conference. San Antonio, Texas, Hyatt Regency San Antonio Riverwalk (March 6-7, 2018).

11. S. Bianco and F. Tisato. "Sensor Placement Optimization in Buildings," Image Processing: Machine Vision Applications V 8300 (2012): 830003 . International Society for Optics and Photonics.

12. M. R. Brambley, P. Haves, S. C. McDonald, P. Torcellini, D. Hansen, D. R. Holmberg, and K. W. Roth. Advanced Sensors and Controls for Building Applications: Market Assessment and Potential R\&D Pathways (No. PNNL-15149). EERE Publication and Product Library, Washington, DC (2005).

13. T. Lovett, J. Lee, E. Gabe-Thomas, S. Natarajan, M. Brown, J. Padget, and D. Coley. "Designing Sensor Sets for Capturing Energy Events in Buildings,” Building and Environment 110 (2016): 11-22.

14. P. Bakir. "Evaluation of Optimal Sensor Placement Techniques for Parameter Identification in Buildings," Mathematical and Computational Applications 16, no. 2 (2011): 456-466.

15. X. Liu, B. Akinci, J. H. Garrett, and O. Akin. "Requirements for a Computerized Approach to Plan Sensor Placement in the HVAC Systems," Computing in Civil and Building Engineering, Proceedings of the International Conference 30 (2010): 235-240.

16. P. Kumar, C. Martani, L. Morawska, L. Norford, R. Choudhary, M. Bell, and M. Leach. 'Indoor Air Quality and Energy Management through Real-Time Sensing in Commercial Buildings," Energy and Buildings 111 (2016): 145-153.

17. M. Papadopoulou, B. Raphael, I. F. Smith, and C. Sekhar. "Optimal Sensor Placement for Time-Dependent Systems: Application to Wind Studies around Buildings," Journal of Computing in Civil Engineering 30, no. 2 (2015): 04015024. 
18. W. Tian, Y. Fu, Q. Wang, T. A. Sevilla, and W. Zuo. "Optimization on Thermostat Location in an Office Room Using the Coupled Simulation Platform in Modelica Buildings Library: A Pilot Study," In the 4th International Conference on Building Energy and Environment (2018).

19. J. V. Cree, A. Dansu, P. Fuhr, S. M. Lanzisera, T. McIntyre, R. T. Muehleisen, M. Starke, P. Banerjee, T. Kuruganti, and C. Castello. Sensor Characteristics Reference Guide (No. PNNL-22484). Pacific Northwest National Laboratory, Richland, Washington (2013).

20. N. Clements, R. Zhang, A. Jamrozik, C. Campanella, and B. Bauer. "The Spatial and Temporal Variability of the Indoor Environmental Quality during Three Simulated Office Studies at a Living Lab," Buildings 9, no. 3 (2019): 62.

21. C. Jiang, Y. C. Soh, and H. Li. "Two-Stage Indoor Physical Field Reconstruction from Sparse Sensor Observations," Energy and Buildings 151 (2017): 548-563.

22. X. Chen and X. Li. "Virtual Temperature Measurement for Smart Buildings via Bayesian Model Fusion," in 2016 IEEE International Symposium on Circuits and Systems (2016): 950-953.

23. Y. Yu, D. Woradechjumroen, and D. Yu. "A Review of Fault Detection and Diagnosis Methodologies on AirHandling Units," Energy and Buildings 82 (2014): 550-562.

24. S. Wang and F. Xiao. "AHU Sensor Fault Diagnosis Using Principal Component Analysis Method," Energy and Buildings 36, no. 2 (2004): 147-160.

25. Y. Chen, S. Huang, and D. Vrabie. "A Simulation Based Approach for Impact Assessment of Physical Faults: Large Commercial Building HVAC Case Study (No. PNNL-SA-132276). Pacific Northwest National Laboratory, Richland, Washington (2018).

26. A. Andriamamonjy, D. Saelens, and R. Klein. "An Auto-Deployed Model-Based Fault Detection and Diagnosis Approach for Air Handling Units Using BIM and Modelica," Automation in Construction 96 (2018): 508-526.

27. Y. Zhao, J. Wen, F. Xiao, X. Yang, and S. Wang. "Diagnostic Bayesian Networks for Diagnosing Air Handling Units Faults-Part I: Faults in Dampers, Fans, Filters, and Sensors," Applied Thermal Engineering 111 (2017): $1,272-1,286$.

28. H. Sharma, U. Vaidya, and B. Ganapathysubramanian. "A Transfer Operator Methodology for Optimal Sensor Placement Accounting for Uncertainty," Building and Environment 155 (2019): 334-349.

29. N. Kocyigit. "Fault and Sensor Error Diagnostic Strategies for a Vapor Compression Refrigeration System by Using Fuzzy Inference Systems and Artificial Neural Network," International Journal of Refrigeration 50 (2015): 69-79.

30. A. Behfar, D. Yuill, and Y. Yu. "Supermarket System Characteristics and Operating Faults (RP-1615)," Science and Technology for the Built Environment 24, no. 10 (2018): 1,104-1,113.

31. C. Francis, G. Maidment, and G. Davies. "An Investigation of Refrigerant Leakage in Commercial Refrigeration," International Journal of Refrigeration 74 (2017): 12-21.

32. W. Kim and S. Katipamula. "A Review of Fault Detection and Diagnostics Methods for Building Systems," Science and Technology for the Built Environment 24, no. 1 (2018): 3-21.

33. D. G. Eliades, M. P. Michaelides, C. G. Panayiotou, and M. M. Polycarpou. "Security-Oriented Sensor Placement in Intelligent Buildings," Building and Environment 63 (2013): 114-121.

34. Y. L. Chen and J. Wen. "The Selection of the Most Appropriate Airflow Model for Designing Indoor Air Sensor Systems," Building and Environment 50 (2012): 34-43.

35. Z. Du, P. Xu, X. Jin, and Q. Liu. "Temperature Sensor Placement Optimization for VAV Control Using CFDBES Co-Simulation Strategy," Building and Environment 85 (2015): 104-113.

36. C. Martín-Gómez, M. Vidaurre-Arbizu, and M. Eguaras-Martínez. "Sensor Placement for BPM Analysis of Buildings in Use to Implement Energy Savings through Building Performance Simulation," Journal of Engineering and Architecture 2, no. 2 (2014): 119-133. 
37. D. Kim, J. E. Braun, E. M. Cliff, and J. T. Borggaard. "Development, Validation, and Application of a Coupled Reduced-Order CFD Model for Building Control Applications," Building and Environment 93 (2015): 97-111.

38. D. Yoganathan, S. Kondepudi, B. Kalluri, and S. Manthapuri. "Optimal Sensor Placement Strategy for Office Buildings Using Clustering Algorithms," Energy and Buildings 158 (2018): 1,206-1,225.

39. M. Arnesano, G. M. Revel, and F. Seri. "A Tool for the Optimal Sensor Placement to Optimize Temperature Monitoring in Large Sports Spaces," Automation in Construction 68 (2016): 223-234.

40. T. Seabrook. "Optimal Placement Strategies of Minimum Effective Sensors for Application in Smart Buildings," 2016.

41. T. Kuruganti, D. Fugate, N. Bourassa, and N. Brown. "Sensor Requirement Document." (No. ORNL/TM59426) Oak Ridge National Laboratory, Oak Ridge, Tennessee (2015).

42. "Sensors in HVAC and Appliance Area." Oak Ridge National Laboratory, Oak Ridge, Tennessee.

43. H. Han, B. Gu, T. Wang, and Z. R. Li. "Important Sensors for Chiller Fault Detection and Diagnosis (FDD) from the Perspective of Feature Selection and Machine Learning," International Journal of Refrigeration 34, no. 2 (2011): 586-599.

44. Y. Chen and L. Lan. "Fault Detection, Diagnosis and Data Recovery for a Real Building Heating/Cooling Billing System," Energy Conversion and Management 51, no. 5 (2010): 1,015-1,024.

45. M. Yuwono, Y. Guo, J. Wall, J. Li, S. West, G. Platt, and S. W. Su. "Unsupervised Feature Selection Using Swarm Intelligence and Consensus Clustering for Automatic Fault Detection and Diagnosis in Heating Ventilation and Air Conditioning Systems," Applied Soft Computing 34 (2015): 402-425.

46. X. Zhao, M. Yang, and H. Li. "A Virtual Condenser Fouling Sensor for Chillers," Energy and Buildings 52 (2012): 68-76.

47. K. Yan, L. Ma, Y. Dai, W. Shen, Z. Ji, and D. Xie. "Cost-Sensitive and Sequential Feature Selection for Chiller Fault Detection and Diagnosis," International Journal of Refrigeration 86 (2018): 401-409.

48. Y. Guo, G. Li, H. Chen, J. Wang, M. Guo, S. Sun, and W. Hu. "Optimized Neural Network-Based Fault Diagnosis Strategy for VRF System in Heating Mode Using Data Mining," Applied Thermal Engineering 125 (2017): 1,402-1,413.

49. D. Li, Y. Zhou, G. Hu, and C. J. Spanos. "Optimal Sensor Configuration and Feature Selection for AHU Fault Detection and Diagnosis," IEEE Transactions on Industrial Informatics 13, no. 3 (2016): 1,369-1,380.

50. W. Kim and J. E. Braun. "Development and Evaluation of Virtual Refrigerant Mass Flow Sensors for Fault Detection and Diagnostics," International Journal of Refrigeration 63 (2016): 184-198.

51. Z. Wang, Z. Wang, X. Gu, S. He, and Z. Yan. "Feature Selection Based on Bayesian Network for Chiller Fault Diagnosis from the Perspective of Field Applications," Applied Thermal Engineering 129 (2018): 674-683.

52. G. Li, H. Chen, Y. Hu, J. Wang, Y. Guo, J. Liu, H. Li, R. Huang, H. Lv, and J. Li. “An Improved Decision Tree-Based Fault Diagnosis Method for Practical Variable Refrigerant Flow System Using Virtual SensorBased Fault Indicators," Applied Thermal Engineering 129 (2018): 1,292-1,303.

53. S. Narayanan, S. Bengea, Y. Lin, R. Taylor, D. Vrabie, S. Yuan, S. Killough, T. Kuruganti, W. Manges, and K. Woodworth, K. A Wireless Platform for Energy Efficient Building Control Retrofits. United Technologies Research Center East Hartford Connecticut (2012).

54. K. Mittal, J. P. Wilson, B. P. Baillie, S. Gupta, G. M. Bollas, and P. B. Luh. "Supervisory Control for Resilient Chiller Plants under Condenser Fouling," IEEE Access 5 (2017): 14,028-14,046.

55. S. Wang, Q. Zhou, and F. Xiao. "A System-Level Fault Detection and Diagnosis Strategy for HVAC Systems Involving Sensor Faults," Energy and Buildings 42, no. 4 (2010): 477-490.

56. Y. Hu, H. Chen, J. Xie, X. Yang, and C. Zhou. "Chiller Sensor Fault Detection Using a Self-Adaptive Principal Component Analysis Method," Energy and Buildings 54 (2012): 252-258.

57. Z. Du, B. Fan, J. Chi, and X. Jin. "Sensor Fault Detection and Its Efficiency Analysis in Air Handling Unit Using the Combined Neural Networks," Energy and Buildings 72 (2014): 157-166. 
58. J. Verhelst, G. Van Ham, D. Saelens, and L. Helsen. "Economic Impact of Persistent Sensor and Actuator Faults in Concrete Core Activated Office Buildings," Energy and Buildings 142 (2017): 111-127.

59. K. Bruton, P. Raftery, N. Aughney, M. Keane, and D. O'Sullivan. "Development of an Automated Fault Detection and Diagnosis Tool for AHUs," 2012.

60. S. Wu and J. Q. Sun. "Cross-Level Fault Detection and Diagnosis of Building HVAC Systems," Building and Environment 46, no. 8 (2011): 1,558-1,566.

61. F. M. Alsaleem, R. Abiprojo, J. Arensmeier, and G. Hemmelgarn. "HVAC System Cloud Based Diagnostics Model," (2014).

62. M. Basarkar, X. Pang, L. Wang, P. Haves, and T. Hong. Modeling and Simulation of HVAC Faults in EnergyPlus (No. LBNL-5564E). Lawrence Berkeley National Laboratory, Berkeley, California (2011).

63. M. Mossolly, K. Ghali, and N. Ghaddar. "Optimal Control Strategy for a Multi-Zone Air Conditioning System Using a Genetic Algorithm," Energy 34, no. 1 (2009): 58-66.

64. P. D. Moroşan, R. Bourdais, D. Dumur, and J. Buisson. "Building Temperature Regulation Using a Distributed Model Predictive Control," Energy and Buildings 42, no. 9 (2010): 1,445-1,452.

65. P. May-Ostendorp, G. P. Henze, C. D. Corbin, B. Rajagopalan, and C. Felsmann. "Model-Predictive Control of Mixed-Mode Buildings with Rule Extraction," Building and Environment 46, no. 2 (2011): 428-437. 